\title{
Zero-a-seis
}

\section{Formação docente na educação infantil: Desafios contemporâneos para a formação permanente}

Resumo: Este artigo aborda a formação permanente de professores de educação infantil no Brasil. Para isso, apresenta as dificuldades existentes na qualidade da formação inicial e continuada dos professores da primeira etapa da Educação Básica, ressaltando os principais desafios enfrentados por estes profissionais. Através de pesquisa de campo realizada com a participação de 100 (cem) professoras da Educação Infantil de Campos dos Goytacazes/RJ/Brasil, constatouse a dificuldade vivenciada pelas professoras no que diz respeito à qualidade tanto da formação inicial que receberam, quanto da formação continuada que tem sido oferecida pelo poder público. Sendo assim, objetiva-se gerar reflexão acerca do que deve ser feito pelas autoridades, principalmente quanto à necessidade de investimentos nessa área, estimulando o aperfeiçoamento profissional contínuo, visando uma formação de qualidade, que permita a aquisição de novos saberes e competências para atender integralmente às especificidades da criança.

Palavras-chave: Educação Infantil; Formação Permanente; Qualidade Educacional

\section{Teacher training in early childhood education: contemporary challenges for continuing training}

Abstract: This article discusses the ongoing training of early childhood teachers in Brazil. For this, the existing features in the quality of initial and continuing teachers of the first stage of basic education training difficulties, highlighting the main challenges faced by these professionals. Through field research conducted with the participation of one hundred (100) teachers from kindergarten of oytacazes/RJ/Brazil, there was the difficulty experienced by teachers with regard to the quality of both initial training they received, as the continuing education that has been offered by the government. Thus, the objective is to generate reflection on what should be done by the authorities, especially regarding the need for investment in this area, encouraging continuous professional development, seeking quality education, enabling the acquisition of new knowledge and skills to meet fully the specificities of the child.

Keywords: Childhood Education; Continuing Education; Educational Quality

\footnotetext{
I Mestrado em Cognição e Linguagem pela Universidade Estadual do Norte Fluminense Darcy Ribeiro. Professora do Curso de Licenciatura em Pedagogia. Instituto Superior de Educação Professor Aldo Muylaert (ISEPAM)/Campos dos Goytacazes/RJ.
}

2 Licenciada em Pedagogia. Instituto Superior de Educação Professor Aldo Muylaert (ISEPAM)/Campos dos Goytacazes/RJ. 
odo profissional é desafiado a renovar permanentemente seus conhecimentos e diferente. Isto significa que o docente deve encontrar-se num processo formativo contínuo, a fim de alcançar uma prática de qualidade, que atenda o público infantil em toda sua potencialidade.

Portanto, pressupõe-se que a educação infantil e, consequentemente, o profissional que trabalha nessa modalidade, devem ser vistos com um novo olhar, isto é, com uma perspectiva pedagógica, o que demanda atualização dos conhecimentos por parte do professor, de maneira a refletir essa aprendizagem em sua prática cotidiana.

Entretanto, o que se percebe atualmente é que a formação permanente ainda encontra-se muito distante do ideal, sendo muitas vezes um fator desestimulante para os profissionais de magistério. Sendo assim, buscou-se investigar a formação docente do professorado de educação infantil. Portanto, o objetivo desse trabalho é apresentar os principais desafios enfrentados pelos professores de Educação Infantil em seu processo de formação permanente.

O trabalho foi organizado em dois momentos visando o melhor entendimento sobre a temática discutida. No momento inicial foram apresentados aspectos introdutórios acerca da formação permanente, investigando como ocorre e quais as principais dificuldades encontradas, especialmente no contexto dos professores de educação infantil.

A seguir, apresenta-se a pesquisa de campo com a utilização da técnica de questionário, contando com a participação de 100 professores da rede municipal de Campos dos Goytacazes. Os questionários foram analisados e interpretados para auxiliar nas discussões levantadas sobre a formação contínua de docentes da educação infantil.

Através da utilização de referenciais teóricos como: Perrenoud (2000), Imbernón (2009), dentre outros, ressalta-se a importância da averiguação da temática referida e espera-se contribuir para o debate a fim de gerar reflexão sobre o processo formativo contínuo dos professores por parte dos órgãos responsáveis e também auxiliar a classe docente a inserir-se numa busca permanente por sua especialização. 
Segundo Perrenoud (2000), a formação contínua ou permanente é uma das principais competências que os profissionais deverão dar ênfase, pois é um meio de manter-se sempre atualizado e de desenvolver outras competências tão necessárias à prática docente, como articular e conduzir situações de aquisição de aprendizagem, gerir o desenvolvimento pedagógico, perceber e progredir dispositivos de diferenciação, abranger os educandos em sua aprendizagem e em sua produção, trabalhar nos princípios da coletividade, estar envolvido na administração escolar, esclarecer e englobar os pais, utilizar novas tecnologias, e encarar os deveres e os dilemas éticos da profissão.

A escola não é um fenômeno inerte, isto é, encontra-se em constante transformação, diante de pessoas que se modificam, paradigmas e ideologias que se renovam. Daí a importância de uma formação permanente, "o que ressalta o fato de que os recursos cognitivos mobilizados pelas competências devem ser atualizados, adaptados a condições de trabalho em evolução". (PERRENOUD, 2000, p. 156).

As práticas pedagógicas vêm sofrendo alterações profundas, porém num ritmo reduzido. Nos tempos atuais vão surgindo novas problemáticas na profissão docente, como a falta de um bom diálogo entre os pais e o educador, a ausência de uma avaliação formativa e uma pedagogia diferenciada etc. Espera-se que esses desafios possam ser resolvidos de forma satisfatória.

Para alcançar um novo patamar, faz-se necessária uma reestruturação nos saberes adquiridos da formação inicial, mais que isso, torna-se necessário criar novas competências que englobem de uma forma geral as instituições educacionais.

Desde o princípio a formação continuada refere-se às práticas profissionais, mas na íntegra faz pouco tempo que parte desse pressuposto. A capacidade de conhecer sua prática é na realidade a base de uma autoformação.

Portanto, formar não pode ser visto como sinônimo de fazer cursos e sim conhecer, transformar a partir de inúmeras metodologias pessoais e coletivas que farão parte de sua formação. Dentre tais metodologias, podem ser consideradas a prática da leitura, a experimentação, o trabalho colaborativo e a reflexão pessoal regular. Essa realidade ocorrerá através do procedimento denominado prática reflexiva.

Reflexivo: o adjetivo presta-se a confusão. Toda prática é reflexiva, no duplo sentido em que seu autor reflete para agir e estabelece a posteriori uma relação reflexiva com a ação realizada. Uma parte de nossa vida mental consiste em pensar no que vamos fazer, no que fazemos, no que fizemos. Todo ser humano é um prático reflexivo. 
Insiste-se nisso para convidar a uma reflexão mais metódica que não seja movida apenas por suas motivações habituais- angústia, preocupação de antecipar, resistência do real, regulação ou justificativa da ação-,mas por uma vontade de aprender metodicamente com a experiência e de transformar sua prática a cada ano. (PERRENOUD, 2000, p. 160)

Saber analisar e explicitar sua prática significa permitir uma lucidez profissional que não pode ser vista como absoluta nem definitiva. A profissionalização através do comprometimento com o ensino evidencia o papel de constatar junto a seu interlocutor os momentos problemáticos e caso não sejam solucionados, poderia contar-se com uma reflexão do que outros profissionais teriam feito diante dos mesmos educandos e das mesmas circunstâncias.

Outra questão importante dentro dessa perspectiva é que nem sempre a reflexão e o treinamento serão os principais fatores de como aprender a fazer. Existem situações que exigem experiência por parte do professor.

Dessa forma, a lucidez profissional informa quando se pode caminhar pelas condições que a situação oferece (individualidade ou em coletivo), e quando se faz necessário utilizar métodos de autoformação, como leitura, pesquisa, acompanhamento de projeto, visando apresentar novos conhecimentos de ensino-aprendizagem.

Em outras palavras, isso significa que não pode haver um único modelo para os educadores adotarem em seu cotidiano e sim cabe aos mesmos adaptá-los ou reconstruí-los de modo a entender suas problemáticas reais.

Outro ponto de análise refere-se a não obrigatoriedade da formação permanente.

Quando ela não é obrigatória, muitos professores escapam
completamente daformação contínua. Alguns deles formam-se como
autodidatas, prescindem da formação contínua institucional, sem que
suas competências cessem de se desenvolver. Outros, que
infelizmente representam mais do que uma margem, vivem com os
conhecimentos de sua formação inicial e de sua experiência pessoal. A
urgência seria fazê-los entrar no circuito da formação contínua, se
possível por vias que não reforcem imediatamente a ideia de que eles
nada têma esperar dela... (PERRENOUD, 2000, p. I63)

Para aqueles que optarem por desenvolver-se e adquirir conhecimento numa perspectiva de se orientar frente às inúmeras ofertas de cursos, sua formação provavelmente será beneficiada.

Para Imbernón (2009) é imprescindível que futuramente haja mudanças significativas na formação inicial e continuada, de modo a assegurar uma nova escolarização democrática da sociedade, formando cidadãos críticos. Outro fator importante nessa perspectiva diz respeito ao papel do educador, que deverá participar de todo o processo da formação, desde o planejamento à avaliação. Atualmente, a formação permanente tornou-se um meio para se alcançar sucesso nas 
reformas educacionais. No entanto, muitas localidades mantiveram-se dominadas por políticas conservadoras, com uma formação descontextualizada das problemáticas sociais.

Para romper com essa visão conservadora é necessário assumir uma perspectiva crítica de educação e formação. Essa nova prática educativa possui função libertadora, combatendo qualquer forma de dominação, visando a transformação social.

Imbernón (2009) conceitua o que seria uma nova alternativa educacional:

Para criar uma nova alternativa educativa, devemos tambémanalisar e
contrapor uma nova visão da educação, que sustenta uma
determinada formação, contra os teóricos e práticos do
"perenialismo" ("voltar ao básico", "deve-se ensinar assim", "a
democracia é a culpada", "os professores são os culpados",
"perderam-se os valores", "é preciso separar e classificar o alunado"
etc.) que voltaram a aparecer em alguns Estados e que revelam uma
ideologia conservadora e um elitismo academicista, que os leva a
considerar certas coisas melhores que outras: por exemplo, a
Universidade como ápice do conhecimento formativo, a desconfiança
no professor e mais na professora, o discurso teórico como acúmulo
de sabres e comparação do intelectual e da tradição cultural ocidental
como superior e única, desprezando outras identidades e
contribuições culturais. (IMBERNÓN, 2009, p. 44)

Para assumir essa nova formação numa perspectiva crítica, o docente deve promover seu desenvolvimento pessoal, profissional e institucional, potencializando seu trabalho colaborativo, permitindo a transformação de sua prática.

Além disso, outro fator necessário para auxiliar nesse novo panorama formativo é que se estabeleça um diálogo entre os pares e a comunidade, promovendo uma ponte entre o contexto social e o docente, criando assim uma nova concepção de educar.

Neste contexto, este artigo volta a atenção aos professores da educação infantil, a fim de investigar como vem se desenvolvendo a formação continuada destes profissionais. Isto porque, atualmente, percebe-se uma preocupação acerca do desenvolvimento no bem estar do aluno da educação infantil, tanto no que diz respeito a seu âmbito pessoal quanto pedagógico. As indagações em relação à qualidade na primeira etapa da educação básica ressaltam a afirmação de que para trabalhar com as especificidades desse público torna-se imprescindível a formação e a qualificação dos profissionais do magistério.

A Lei de Diretrizes e Bases da Educação Nacional (LDBEN no 9394/96) exige como formação mínima para atuar na sala de aula com crianças de zero a cinco anos, o ensino médio na categoria normal, todavia evidencia a importância do curso superior. Entretanto, ainda existe um grande número de professores fora dos parâmetros propostos.

Para Kishimoto (1999), o despreparo para a docência torna-se mais intenso em relação às creches: 
A situação nas creches é mais complicada. $\bigcirc$ tradicional abandono e descaso, fruto de uma política de exclusão desses profissionais no campo da educação, reflete-se no contingente de leigos que não se pode precisar pela falta de estatísticas. Mesmo nos grandes centros urbanos, a qualificação requerida é, ainda, de ensino fundamental. Há, certamente, um grande contingente que sequer completou o ensino fundamental. Que soluções serão adotadas? Expulsá-los do sistema ou aproveitá-los por meio de programas de qualificação em parceria com organizações diversas? Infelizmente a desativação precoce do magistério de nível médio parece indicar a primeira opção. (KISHIMOTO, 1999, p.63)

Para Cruz (2010), o processo contínuo de formação para os profissionais da educação infantil deve buscar aprimorar cada vez mais a prática dos mesmos. Neste contexto, surge uma nova concepção de formação voltada para estes professores que ultrapassa a visão tradicional, e incorpora em seu modelo a contextualização do estabelecimento a qual esse profissional atua, afirmando que a prática docente é influenciada diretamente pela instituição trabalhada. "Essa perspectiva também inova ao inserir a formação continuada dos professores num processo mais amplo que inclui a investigação e a intervenção no seu contexto profissional” (CRUZ, 2010, p. 361).

O processo formativo do educador na perspectiva reflexiva valoriza o desenvolvimento pessoal-profissional dos professores e dos estabelecimentos escolares, visando almejar condições de trabalho propícias para "formação como contínua dos professores, no local de trabalho, em redes de autoformação, e em parceria com outras instituições de formação”. (PIMENTA, 2009, p. 31).

Isso ocorre porque trabalhar com os saberes sofrendo intervenção da globalização, das tecnologias, da multiculturalidade, e dos novos perfis exigidos no mercado trabalhista, visando formar o público infantil e jovem, requer uma formação permanente.

Percebe-se, então, a importância de haver um momento na formação contínua do professor que privilegie a reflexão crítica sobre a prática. É através do refletir sobre as ações de hoje, que será possível melhorar a prática de amanhã. "O próprio discurso teórico, necessário à reflexão crítica, tem de ser tal modo concreto que quase se confunda com a prática”. (FREIRE, 2011, p. 40).

Assim, a formação como parte integrante da educação, também deve ser uma ação continuada, que através do seu progresso temporal vá se modificando, atendendo as necessidades do momento histórico em que se encontra.

Pesquisando a formação do professor de educação infantil

Pretende-se, através da pesquisa de campo, identificar como é percebido o processo de formação por parte dos educadores da primeira etapa da educação básica, principalmente a formação contínua, a fim de auxiliar no entendimento sobre a temática deste trabalho. 
O público-alvo da pesquisa foi constituído de professoras da Educação Infantil, todas regentes de turmas da rede pública municipal de Campos dos Goytacazes/RJ/Brasil. A amostra foi composta por 100 professoras que aceitaram contribuir com esta pesquisa, respondendo a um questionário.

O questionário contou com 08 (oito) questões, sendo 04 (quatro) questões fechadas e 04 (quatro) abertas. A elaboração das perguntas visou constatar o entendimento sobre a formação dos professores e para isto, optou-se por poucas perguntas, no intuito de facilitar o preenchimento/retorno dos questionários.

Os questionários foram distribuídos através da visitação às instituições de educação infantil. Também ocorreu um auxílio por parte de algumas colegas que trabalham diretamente com esse nível educacional e levaram os formulários para que as professores de sua instituição pudessem preencher, a fim de possuir um número satisfatório de formulários para análise. Desta forma, foram reunidos 100 questionários. A tabulação das informações colhidas através do questionário permitiu tecer algumas considerações. As questões apresentadas aos participantes da pesquisa são analisadas a seguir.

A primeira questão do questionário analisava o tempo de serviço do docente. Constatou-se que a amostra era composta por $13 \%$ de professoras com menos de 5 anos na docência, $34 \%$ de 5 a 10 anos, $21 \%$ possuíam de 10 a 15 anos no ofício e 32\% assinalaram a opção de mais de 15 anos na docência.

A próxima questão buscou entender se a formação inicial dessas professoras as preparou para lidar com as especificidades da educação infantil. Observou-se que 53\% relataram que sim, 46\% responderam que não e 1\% não assinalou.

Segundo Cruz (2010), para ocorrer uma formação qualitativa, que atenda as especificidades da educação infantil faz-se necessário uma boa formação e qualificação desses profissionais do magistério. Também é imprescindível que o professor alie duas características fundamentais para

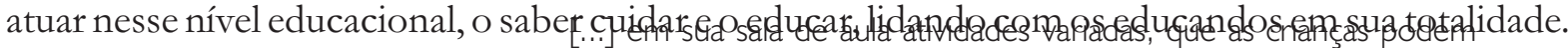

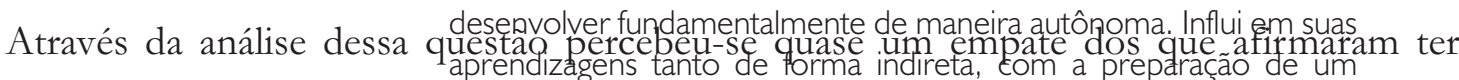

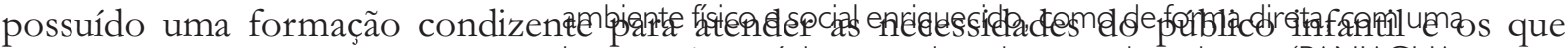

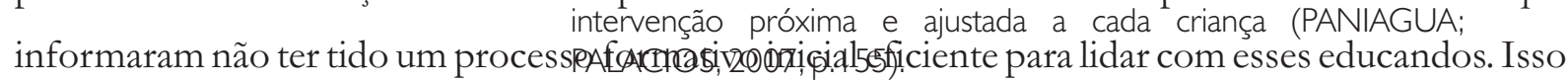
pode indicar uma dificuldade por parte dos cursos de formação de professores em preparar esses profissionais para atuação diária.

A próxima questão aborda de que forma a formação inicial auxilia na prática. O estágio foi a opção mais descrita e respondida por $26 \%$, sendo seguida pelos que relataram que em nada auxiliou ou de forma muito superficial correspondendo a $21 \%$ das entrevistadas. As que informaram que esse 
processo ajudou em diversos aspectos de maneira geral foram 17\%. Outras 15\% citaram o embasamento teórico como fator importante adquirido no processo formativo, $17 \%$ responderam ser um suporte pedagógico e metodológico, enquanto 4\% não responderam.

Para Pimenta (2004), o estágio é um momento muito importante, pois é uma forma de despertar o estagiário como futuro educador e deve realizar-se como uma forma de pesquisa.

\begin{abstract}
A pesquisa no estágio, como método de formação de futuros professores, se traduz, de um lado, na mobilização de pesquisas que permitem a ampliação e análise dos contextos onde os estágios se realizam; por outro, e em especial, se traduz na possibilidade dos estagiários desenvolverem postura e habilidades de pesquisador a partir das situações de estágio, elaborando projetos que lhes permitam ao mesmo tempo compreender e problematizar as situações que observam. (PIMENTA, 2004, p.46)
\end{abstract}

Outro fator muito relevante diz respeito às entrevistadas que responderam que em sua formação inicial nada auxiliou em sua atuação cotidiana ou de maneira muito supérflua (21\%). Cruz (2010) afirma de que maneira a formação inicial deve capacitar esses profissionais para sua prática cotidiana:

Para preparar o futuro professor a desenvolver essa prática, a
formação inicial em nível médio e, preferencialmente, no curso de
Pedagogia precisa enfrentar grandes desafios. Entre estes, merecem
maior destaque a formação específica, com conteúdos voltados para a
prática docente na área e a inclusão de temas relativos à Educação
Infantil nas demais disciplinas do curso. (CRUZ, 20 I0, p.356)

Segundo Freire (2011), o conhecimento teórico é um aspecto primordial rumo a uma prática qualitativa, auxiliando assim no sucesso escolar. Isso significa que teoria e prática devem andar sempre juntas, complementando-se.

Através dos relatos abordados, observa-se que o primeiro contato com a prática docente, isto é, o estágio tem um papel muito importante para os formandos, isso porque através dessa observação poderão conhecer as principais dificuldades da profissão, refletir sobre os conhecimentos teóricos aprendidos, analisar determinadas situações, ou seja, entender como esse profissional atua na prática, e a partir daí criar sua própria metodologia, seu próprio modo de agir.

Perguntadas se existem fatores que desestimulam sua prática, $84 \%$ assinalaram que sim e apenas 16\% responderam negativamente. As que optaram pela opção afirmativa descreveram os principais fatores que causam esse estresse: 30\% citaram como resposta as péssimas condições de trabalho, $20 \%$ relataram a desvalorização e a baixa remuneração, $15 \%$ criticaram a falta de parceria com a família, 12\% descreveram a falta de comprometimento da gestão e do órgão municipal, e 7\% atribuíram a falta de interesse dos educandos como uma característica desestimulante.

Para Freire (2011), o processo de reivindicação e luta por parte da classe do professorado por 
melhorias em seu local de trabalho é uma das principais condições rumo a uma prática mais prazerosa e qualitativa.

\begin{abstract}
Se há algo que os educandos brasileiros precisam saber, desde a mais tenra idade, é que a luta em favor do respeito aos educadores e à educação inclui que a briga por salários menos imorais é um dever irrecusável e não só um direito deles. A luta dos professores em defesa de seus direitos e de sua dignidade deve ser entendida como um momento importante de sua prática docente, enquanto prática ética. (FREIRE, 20 I I, p.65)
\end{abstract}

Gadotti (2007) informa sobre a importância do contexto familiar, principalmente para a educação infantil, pois é a primeira comunidade de aprendizagem, é o primeiro contato social da criança, constituindo um âmbito fundamental para o desenvolvimento infantil. Assim, a família deverá auxiliar e complementar o trabalho do docente, dessa maneira o educando aprenderá com maior facilidade e rapidez.

Compreende-se o porquê desses aspectos estarem no topo da lista de insatisfação docente, já que se faz necessário possuir um ambiente favorável à aprendizagem, com condições dignas de trabalho. Também é necessário elevar o status da profissão, valorizando-a, pagando salários condizentes com a importância do trabalho desenvolvido.

Perguntadas sobre quais as competências necessárias para ser um bom educador, 48\% responderam amar a profissão e gostar do que fazem, 33\% das educadoras pesquisadas descreveram o comprometimento como característica fundamental para atuar na profissão, $17 \%$ relataram a importância de estar sempre buscando conhecimento e se atualizando, e $2 \%$ não responderam.

Gadotti (2007) explicita que não basta apenas gostar de criança para tornar-se um professor de educação infantil, torna-se necessário possuir uma formação ético-política:

Escolher a profissão de professor não é escolher uma profissão
qualquer. Na maioria das vezes essa escolha se dá por instituição.
Muitas professoras, quando perguntadas porque escolheram essa
profissão respondem: "porque gosto de criança". É uma resposta
correta e significativa, mas não é levada em conta no seu processo de
formação. Em geral, a sua formação limita-se a aspectos técnico-
pedagógico e não ético-políticos que seriam mais afinados com os
motivos de sua escolha por causa da confusão que ainda é
frequentemente feita entre o papel da mãe e de professora, sobretudo
na educação infantil. (GADOTTI, 2002, p. I0)

Dessa maneira, Gadotti (2007) explicita as competências necessárias para ser um bom profissional, referindo-se à segunda opção mais descrita na pergunta, o comprometimento. "Porque ser comprometido, engajar-se, ser ético, faz parte da sua competência como professor" (GADOT'TI, 2002, p. 45).

Isso evidencia que não basta apenas se identificar com o público infantil, pois atuar na 
docência significa alcançar meios para promover desenvolvimento infantil, engajando-se numa formação permanente para estar sempre renovando seus saberes e competências, visando sua melhoria profissional.

$\mathrm{Na}$ questão seguinte indagou-se sobre com que frequência participavam de cursos de formação continuada. Do total das entrevistadas, $60 \%$ responderam que possuem cursos bimestralmente, 17\% afirmaram não possuir, 21\% assinalaram a opção mensalmente e 2\% não respondeu.

Destaca-se o número de pessoas que relataram não possuir formação continuada, mais precisamente $17 \%$, pois segundo Perrenoud (2000), esse é um dos principais aspectos para a prática docente de qualidade. Imbernón (2009) também alerta sobre a importância da formação permanente, concebendo-a como um fator que objetiva promover a melhoria da prática e, consequentemente, da aprendizagem dos educandos.

Somente quando o professorado vê que o novo programa formativo
ou as possíveis mudanças da prática que lhes é oferecida repercutem
na aprendizagem de seus estudantes, mudam suas crenças e atitudes
de forma significativa e supõem um benefício para o alunato e a forma
de exercer a docência, então, abre-se a forma de ver a formação não
tanto como uma "agressão" externa, mas como um benefício
individual ou coletivo. (IMBERNÓN, 2009, p. 27)

Nota-se a ausência da formação permanente, um aspecto muito importante para lidar com as mudanças e as necessidades atuais que o mundo globalizado vem acarretando.

A próxima questão interroga sobre a formação contínua, indagando se os assuntos abordados nos cursos oferecidos condizem com a realidade profissional das professoras. Das docentes pesquisadas, 53\% responderam que não, pois os aspectos trabalhados na formação contínua não respondem à necessidade real da sala de aula, 42\% informaram que sim, e apenas 5\% não responderam.

Perrenoud (2000) afirma que a formação contínua não pode ser vista apenas como sinônimo de cursos, e sim deve ser um processo de aquisição de conhecimentos e transformação de metodologia para, dessa maneira, atender às necessidades da prática diária. O âmbito escolar deve encontra-se em constante transformação, daí a importância de uma formação continuada que atenda a essas novas exigências.

Imbernón (2009) aborda a questão das dificuldades enfrentadas pela classe docente em determinados programas de formação. Isso ocorre pelo fato de serem cópias padronizadas, sem levar em conta as realidades e as necessidades do contexto do qual os professores fazem parte. 
É difícil com um pensamento educativo único predominante (currículo igual, gestão idêntica, normas iguais, formação igual para todos etc.) desmascarar o currículo oculto que se transmite na formação do professorado e descobrir outras maneiras de ver a educação e de interpretar a realidade. (IMBERNÓN, 2009, p. I5)

Isso explicita a dificuldade de aceitação por parte dos professores em relação à formação contínua, pois, em grande parte, os cursos, os assuntos e aspectos trabalhados não se referem às principais necessidades dos vivenciadas. Indica-se, nesse trabalho, que a situação poderia ser solucionada se houvesse interesse por parte dos órgãos formadores de pesquisar e trabalhar em conjunto com os educadores, buscando entender junto a eles quais são suas maiores dificuldades, as maiores demandas a serem trabalhadas etc.

A última questão refere-se às temáticas que deveriam ser trabalhadas nos programas de formação continuada. Das profissionais entrevistadas, 40\% identificaram a importância de serem trabalhadas questões sobre as problemáticas cotidianas e os primeiros socorros ao público infantil, $19 \%$ citaram a inclusão como um aspecto que deve ser mais trabalhado, 16\% informaram a questão de como lidar com a indisciplina e a violência escolar, 9\% relataram assuntos ligados à arte e à ludicidade, $7 \%$ afirmaram que a dificuldade de aprendizagem e valores deveriam fazer parte da pauta dos cursos, 3\% relataram a sexualidade, e $6 \%$ não responderam.

Para Imbernón (2009), a formação continuada deve atender a situações problemáticas e para isso faz-se necessário que o docente torne-se protagonista de sua própria formação.

\footnotetext{
A formação permanente do professorado na análise da complexidade dessas situações problemáticas requer necessariamente dar a palavra aos protagonistas da ação, responsabilizá-los por sua própria formação e desenvolvimento na instituição educativa na realização de projetos de mudança. (IMBERNÓN, 2009, p. 53)
}

Através da análise da pesquisa, percebeu-se que a formação inicial apresenta dificuldades em formar docentes para lidar com as principais problemáticas do contexto escolar. Um dos fatores que causam esse despreparo é a superficialidade teórico-prática que não prepara ou, em alguns casos, não condiz com as necessidades reais encontradas no cotidiano da sala de aula.

Outro aspecto relevante diz respeito aos cursos formativos, que devem atentar às transformações na atualidade, provenientes da globalização, adaptando seus conteúdos, suas metodologias ao que está ocorrendo na sociedade.

Quanto ao processo de formação contínua é necessário deixar de ser visto apenas como um momento de treinamento. Isso significa que nesses programas e cursos devem ser trabalhados aspectos que expressem a real necessidade de cada instituição, passando a ser um momento de reflexão, renovação científica, de experimentação, de ingressar-se no mundo da pesquisa, da leitura e 
de novas descobertas. Esse processo permanente deve ser oferecido com frequência pelos órgãos competentes, estimulando seus profissionais a buscarem novos conhecimentos.

Portanto, percebe-se que a formação inicial e contínua são complementares. Logo, se a primeira tiver sido precária, dificilmente a segunda despertará interesse ou resultados significativos. Porém se ambas forem realizadas através de um processo de qualidade, a probabilidade de formar um professor reflexivo e pesquisador torna-se muito viável. 


\section{Considerações finais}

Ainda persiste a ideia de que a primeira etapa da educação básica, a educação infantil, possui como finalidade apenas cuidar da criança enquanto os pais encontram-se inseridos no trabalho. Isso evidencia o quanto estamos atrelados a perspectivas passadas, ainda que estejamos diante de um mundo globalizado, altamente tecnológico, também conhecido como sociedade do conhecimento.

É necessário romper com esse paradigma e reafirmar a importância da educação infantil, concebendo a criança como um indivíduo capaz de aprender e, para isso, é fundamental que o profissional que vai atuar junto a ela esteja preparado, a fim de desenvolver as potencialidades desse público.

Outro aspecto muito relevante para a formação docente é atrelar formação inicial e contínua, de maneira a complementarem-se. Ambas possuem a finalidade de garantir ao profissional uma base sólida para atuar junto a seu público-alvo. Para isso, faz-se necessário que a classe docente alie-se aos responsáveis pela formação inicial e permanente, para que possam através da reciprocidade entender e trabalhar aspectos direcionados às particularidades de seus educandos, buscando, dessa forma, um trabalho de qualidade.

Nessa perspectiva participativa de formação, surge a necessidade de se trabalhar numa perspectiva reflexiva, havendo condições por parte dos professores de trabalhar conteúdos condizentes com a realidade dos educandos, de acordo com suas características socioculturais, a fim de tornarem-se cidadãos autônomos.

O anseio por uma formação docente que atenda às realidades encontradas na sala de aula gera uma reflexão acerca das respostas da pesquisa de campo realizada. Quando perguntadas se sua formação inicial as preparou para lidar com o público infante, um número relevante de professoras respondeu que não, indicando as dificuldades no processo formativo.

De maneira geral, os resultados da análise dos questionários em relação à formação permanente não foram animadores. Quando indagadas sobre sua formação continuada, parte das professoras afirmou não possuir. Isso aponta para a urgência dos órgãos responsáveis oferecerem e estimularem o aperfeiçoamento de seus profissionais.

Outra situação relevante diz respeito ao número expressivo de educadoras que responderam que os assuntos abordados na formação contínua não condizem com as necessidades reais da sala de aula, o que causa mal-estar entre as docentes, já que o conteúdo da formação permanente oferecida não atende às suas necessidades.

Portanto, a pesquisa de campo indicou deficiências na formação inicial e a ausência de interesse quanto à formação permanente, ainda vista como descontextualizada da prática cotidiana. 
A formação contínua é um meio do professor estar sempre se aperfeiçoando, aprendendo cada vez mais a lidar com situações cotidianas. Por isso, os assuntos abordados devem estar diretamente ligados ao que se passa nessas instituições. Além disso, o professor não deve apenas esperar por parte dos órgãos responsáveis por oportunidades de formação continuada, também deve tornar-se ativo na busca por sua atualização constante.

Dessa maneira, seu conhecimento deve possuir como foco o público alvo com o qual se encontra atuando, nesse caso, crianças de até 5 anos de idade. Assim, não são só os conteúdos devem ser trabalhados pelo professor, mas também outras competências que auxiliarão as crianças no desenvolvimento físico, cognitivo e motor, além de estimular a aquisição de autonomia e a constituição da identidade através de atividades pedagógicas planejadas. 
BRASIL. Ministério da Educação. Lei de Diretrizes e Bases da Educação Nacional n ${ }^{\circ}$ 9.394, de 20 de dezembro de 1996. Brasília, 1996.

CRUZ, Sílvia Helena. A formação inicial e continuada e a profissionalidade específica dos docentes que atuam na educação infantil. In: Frade. Isabel Cristina Alves da Silva (Org). Convergências e tensões no campo da formação e do trabalho docente. Belo Horizonte: Autêntica, 2010.

FREIRE, Paulo. Pedagogia da autonomia: Saberes Necessários à Pratica Educativa. $43^{a}$ Ed. Paz e Terra, 2011.

GADOTTI, Moacir. Boniteza de um sonho: Ensinar-e-aprender com sentido. São Paulo: Cortez, 2002.

INBERNÓN, Francisco. Formação permanente do professorado: novas tendências. São Paulo: Cortez, 2009.

KISHIMOTO, Tizuko Morchida. Políticas de formação profissional para a educação infantil: pedagogia e normal superior. Educação e Sociedade (CEDES), n. 68, 1999.

LIBÂNEO, José Carlos. Adeus professor, Adeus professora?: Novas exigências educacionais e profissão docente. 11 ed. São Paulo: Cortez, 2009.

PERRENOUD, Philippe. Dez novas competências para ensinar. Porto Alegre: Artmed, 2000.

PIMENTA, Selma Garrido. Saberes Pedagógicos e atividade docente- 7.ed- São Paulo: Cortez, 2009. 